\title{
Porphyridium violaceum, eine marine neue Art
}

\author{
Peter Kornmann \\ Biologische Anstalt Helgoland, Meeresstation, Helgoland
}

\begin{abstract}
Porphyridium violaceum, a marine new species. The new species is marine, whereas Porpbyridium purpureum $(=P$. cruentum), first known only from terrestrial habitats, is halophilic and has been found several times in seawater. Porphyridium violaceum differs from the above mentioned species by a larger diameter and the colour of its cells.
\end{abstract}

Uber das Vorkommen von Porphyridium im Meer und die Beziehung solcher Funde zu der terrestrischen Art Porphyridium purpuretum (BORY) Drew \& Ross (1965, syn. Porphyridium cruentum) ist in den letzten Jahren mehrfach ausführlich berichtet worden, so daß sich eine historische Übersicht hier erübrigt. E. G. \& O. PrIngsherm (1956) verglichen zwei Stämme mariner mit drei Stämmen terrestrischer Herkunt und stellten ihre morphologische und physiologische Übereinstimmung fest. Es ist daher sehr wahrscheinlich, daß die von KYLIN (1937) beschriebene Art Porphyridium marinum als mariner Stamm von Porphyridium purpureum anzusehen ist. RIETH (1961, 1962) gelangte bei der Untersuchung eines Porphyridium-Stammes aus dem Mittelmeer zu dem gleichen Ergebnis.

Die neue Art, die ich vor 14 Jahren aus Meerwasser bei List auf Sylt isolierte, unterscheidet sich durch ihre wesentlich dickeren Zellen ganz klar von Porphyridium purpureum. In den Abbildungen 1 und 2 werden die beiden Arten einander gegenübergestellt. Sie wuchsen unter völlig gleichen Kulturbedingungen in Erdschreiberlösung; die Kulturen erhielten täglich 14 Stunden Licht von einer etwa $40 \mathrm{~cm}$ entfernten Tageslicht-Leuchtstofflampe (40 Watt). Ein aus Seewasser von Brixham Harbour isolierter Stamm von Porphyridium purpurewm wurde mir freundlicherweise von Herrn Dr. KocH zur Verfügung gestellt (Nr. 1380-1 d der Sammlung von Algenkulturen in Göttingen, Косн 1964). Weit über den Boden einer Kulturschale verteilte Einzelzellen haben sich nach 7 Tagen zu Gruppen von 8 bis 16 Zellen vermehrt. Die Teilung der Zellen erfolgt ziemlich regelmäßig, jedoch nicht völlig gleichzeitig, so daß die meisten Gruppen ausgewachsene, teilungsfähige Kugeln neben ihren kleineren Tochterzellen enthalten (Abb. 1). Damit ist die Schwankungsbreite ihres Durchmessers in einer frisch angelegten Kultur bestimmt: sie liegt $z$ wischen 5 und $7 \mu$. Diese Maße stimmen mit den von KYLIN (1937) für Porpbyriditum marinum angegebenen überein.

Die Zellen der neuen Art sind erheblich größer, wie die im gleichen Maßstab wiedergegebene Abbildung 2 zeigt. Sie bleiben aber nach den Teilungen im allgemeinen nicht zu Gruppen vereinigt, die Zellen wandern sehr viel aktiver als Porpbyridium purpureum positiv oder negativ phototaktisch je nach der Lichtstärke. In lebhaft wach- 


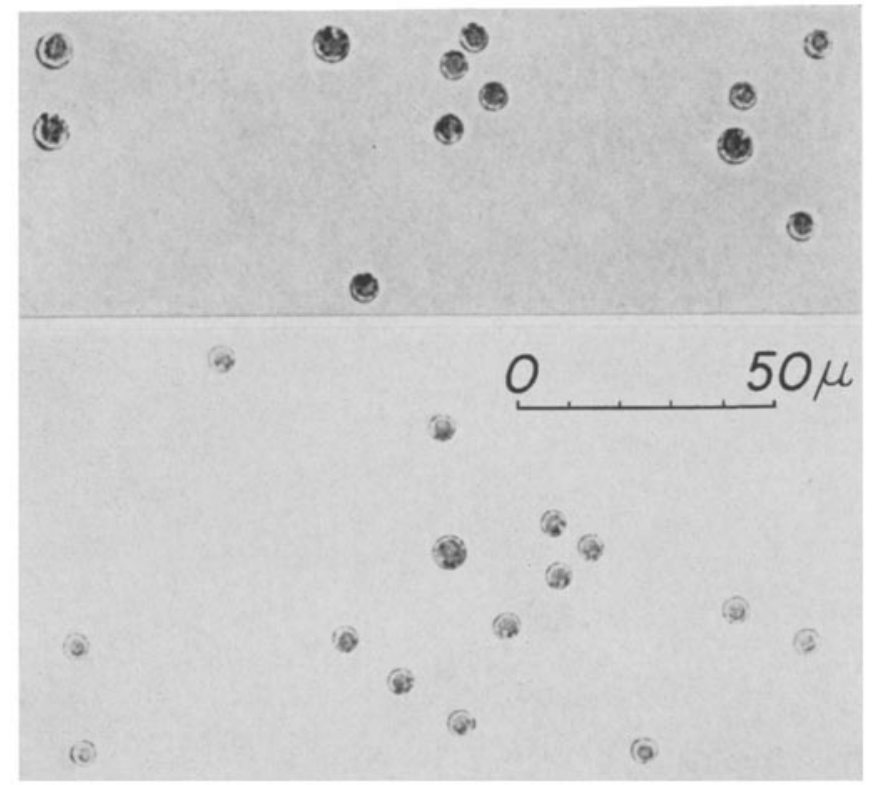

Abb. 1: Porphyridium purpureum. $Z_{W}$ ei aus Einzelzellen entstandene Zellgruppen in einer 7 Tage alten Kultur
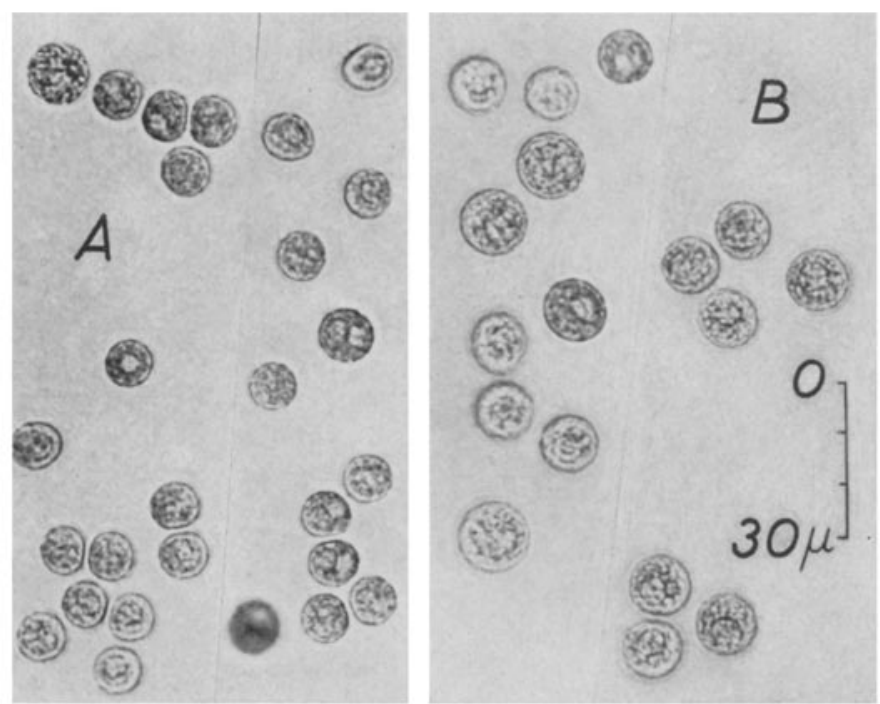

Abb. 2: Porphyridium violacetum. Zellen aus einer 6 Tage alten Kultur, $A$ in jungem, $B$ in ausgewachsenem Zustand

senden Kulturen sind die Zellen nach der während der Dunkelperiode erfolgenden Teilung 8 bis $11 \mu$ dick (Abb. $2 A$ ), sie vergrößern sich im Laufe der 14stündigen Belichtung auf 11 bis $14 \mu$ (Abb. $2 B$ ). Auch in älteren Kulturen weichen die Maße der Zellen 
nicht wesentlich von diesen Werten ab, einzelne Zellen können jedoch über $30 \mu$ groß werden. Es erscheint mir aber zweckmäßig, die Arten nach den Maßen der Zellen in frisch angesetzten und rasch sich vermehrenden Kulturen zu kennzeichnen.

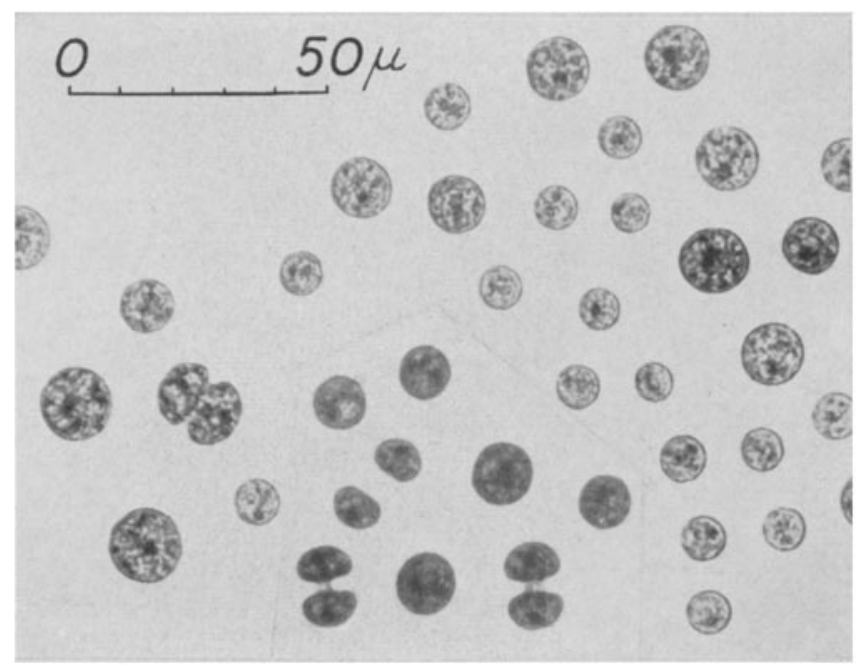

Abb. 3: Porphyridium violaceum nach Färbung mit Eisenhämatoxylin. Zellkerne besonders in den Teilungsparen und kleineren Zellen gut erkennbar

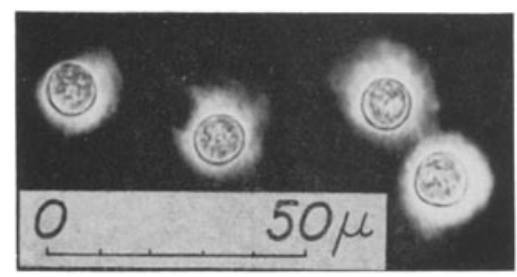

Abb. 4: Porphyridium violacenm. Der breite Gallertmantel um die Zellen ist durch Tusche sichtbar gemacht

Auch durch die violette Farbe ihrer Zellen unterscheidet sich die neue Art von Porphyridium purpureum, die unter den Bedingungen meiner Kulturen rosarot gefärbt sind. In den lebenden Zellen ist das zentrale Pyrenoid deutlich sichtbar, während der sternförmige Chromatophor durch die reichlich gespeicherte Stärke nicht klar erkennbar ist. Der Zellkern färbt sich mit Eisenhämatoxylin nach HANSEN kräftig an (Abb. 3). Die Vermehrung der Zellen erfolgt durch einfache Durchschnürung, deren Ablauf sich unter dem Mikroskop leidht beobaditen läßt (Abb. 3). Bei der Beleuchtungsrhythmik meiner Versuchsanordnung begannen die Teilungen kurz vor der Dunkelphase.

Jede Zelle ist von einer gallertigen Hülle umgeben (Abb. 4). In älteren Kulturen liegen die Zellen dicht in einer homogenen Gallerte eingebettet. 
Außer dem halophilen Porphyridium purpureum enthält die Gattung jetzt einen echten marinen Vertreter. Er wurde zuerst 1951 in einer Rohkultur von Algen aus einem Aquarium des ehemaligen Laboratoriums der Biologischen Anstalt Helgoland auf dem Ellenbogen bei List auf Sylt gefunden. Später wurde die Art auch aus einem flachen Tümpel des Aquarien-Abflußwassers am Vorstrand isoliert. Beide Fundstellen sind seit der Auflösung dieses Laboratoriums nicht mehr vorhanden. Da aber die Aquarien mit Wasser aus dem Wattenmeer versorgt wurden, kann als typischer Fundort der Königshafen bei List auf Sylt gelten.

Diagnosis: Porphyridium violaceum nov. spec.

In cultura abundanter crescens cellulae adultae 11-14 $\mu$, post divisionem 8-11 $\mu$ crassae. Chromatophorum violaceum.

In mari vadoso ad litus insulae Sylt prope List habitans.

Typus in laboratorio Biologische Anstalt Helgoland cultus.

\section{ZUSAMMENFASSUNG}

1. Die neubeschriebene marine Porphyridium-Art unterscheidet sich von dem terrestrisch lebenden, aber auch im Meerwasser gefundenen Porphyridium purpureum durch ihre größeren, violett gefärbten Zellen.

2. Teilung und Wachstum der Zellen von Porphyridium violaceum passen sich dem Belichtungsrhythmus an. Die während der 10stündigen Dunkelheit geteilten Zellen sind 9 bis $11 \mu$ dick, sie vergrößern sich während der Lichtperiode auf 11 bis $14 \mu$.

\section{ZITIERTE LITERATUR}

Drew, K. M. \& Ross, R., 1965. Some generic names in the Bangiophycidae. Taxon 14, 93-99.

Koch, W., 1964. Verzeichnis der Sammlung von Algenkulturen am Pflanzenphysiologischen Institut der Universität Göttingen. Arch. Mikrobiol. 47, 402-432.

KyLiN, H., 1937. Uber eine marine Porphyridium-Art. $K$. fysiogr. Sällsk. Lund Förb. 7, (Nr 10), 1-5.

Pringsheim, E. G. \& Pringshem, O, 1956. Kleine Mitteilungen über Flagellaten und Algen. IV. Porphyridium cruentum und Porpbyridium marinum. Arch. Mikrobiol. 24, 169-173.

Rieth, A., 1961. Ein marines Porphyridium von der Mittelmeerküste bei Neapel und die Berechtigung der Art Porphyridium marinum KYLrN. Biol. Zbl. 80, 429-438.

- 1962. Weitere Beobachtungen an Kulturen von Porpbyridium cruentum (AG.) NaEg. mariner Herkunft. Kulturpflanze 10, 168-194. 